Results Most of the return migrant workers who had long term (>1 years) exposed with solvents, biological or chemical occupation have less than the normal sperm counts than nonmigrant cases. BMI was normal but the mental stress on return migrant workers having more than others. Clinical findings of less than 20 million/mL sperm concentration, progressive motility 32\%, Odds ratios (ORs), after allowing for confounding, were 2.07 (95\% confidence interval (95\% CI) 1.24 to 3.44 ) for 1-3 years exposure to solvents and 3.83 (95\% CI 1.37 to 10.65$)$ for more than 3 years exposure. Chances of fertilization was at least 1-2 year among long term migrant return workers.

Conclusion Occupational hazards in reproductive life is more seen among the mental stress workers. It may be due to improper use occupational safety clothes, equipment etc. Proper counselling, Workplace safety rules and regulation policy should be clearly documentation for all migrant workers. Occupation physician screen all workers health every 3 months. Education, awareness and changing attitude of work style is essential in this globalization era.

\section{P.3.15 SUICIDE TRENDS BY OCCUPATION IN SOUTH AFRICA, 1997 TO 2016}

${ }^{1}$ Tahira Kootbodien, ${ }^{1}$ Kerry Wilson, ${ }^{1}$ Nonhlanhla Tlotleng, ${ }^{1,2}$ Nisha Naicker. ${ }^{1}$ National Institute for Occupational Health, Johannesburg, South Africa; ${ }^{2}$ School of Public Health, Faculty of Health Sciences, University of the Witwatersrand, Johannesburg, South Africa

\subsection{6/OEM-2019-EPI.274}

Background The risk of suicide varies across occupations. However information is limited in South Africa. Surveillance data are vital to raise awareness of suicide risk for effective interventions in workplaces.

Method To assess trends in suicide-related mortality by occupation, we analysed underlying cause of death data and occupation information from vital registration data from Statistics South Africa. Suicide (X60-X84) was coded using the 10th Revision of the International Classification of Diseases (ICD10). Occupation groups were based on the South African Standard Classification of Occupations (SASCO) groups: (1) managers, (2) professionals, (3) technicians, (4) clerks, (5) service workers, (6) skilled agricultural and fishery workers, (7) craft and related trade workers, (8) plant and machine operators and (9) elementary occupations. Multivariate logistic regression analyses were performed to calculate mortality odds ratios (MOR) for occupation groups in men and women, adjusting for age, year of death, education level, marital status and province of death.

Results The 20 year study examined 7113 episodes of suicide in South Africa of all persons of working age from 1997 to 2016. Deaths by suicide increased from $1997(n=93,0.05 \%)$ to $2016(\mathrm{n}=389,0.15 \%$, nptrend, $\mathrm{p}<0.001)$. Among men, the risk of suicide was highest in skilled agricultural and fishery workers $(\mathrm{MOR}=3.0,95 \% \mathrm{CI} 1.75-5.16)$. Among women, risk of suicide were highest in skilled agricultural and fishery workers $(\mathrm{MOR}=2.7,95 \% \mathrm{CI} 1.03-6.84)$ and clerical workers $(\mathrm{MOR}=2.40,95 \%$ CI 1.29-4.46).

Conclusion The results show that agricultural and fishery workers are at highest risk of suicide in men and women of working-age. There is a need for future studies to investigate explanations for the observed differences across occupations, particularly in people employed in lower skill-level groups.
P.3.16 THE ASSOCIATIONS BETWEEN PSYCHOSOCIAL WORK CONDITIONS AND WORK SUSTAINABILITY: FINDINGS FROM A NATIONAL SURVEY OF WORKING PEOPLE IN TAIWAN

Yi-Jing Li*, Hsi-Chen Liu, Yawen Cheng. The Institute Of Health Policy And Management, National Taiwan University, Taipei, Taiwan

\subsection{6/OEM-2019-EPI.275}

Background One of the aspects of work sustainability concerns workers' intention to stay at the current job until retirement age. While psychosocial work conditions are expected to influence workers' intention to stay, its distributions across occupations and the associations with psychosocial work factors have not been well understood.

Methods We analyzed data from a national survey conducted in 2010, consisting of 11209 male and 8189 female workers aged between 25 to 55 years old. Intention to stay at the current job was assessed by a single question: 'Thinking of your health status, would you expect yourself to stay at the current job at age of 60 years old?'. Responses were coded as 'probably yes', 'probably not', 'not sure' and 'not willing'. We regrouped 'probably not' and 'not willing' as 'no intention'. Information concerning age, educational attainment, occupation type and psychosocial work factors were also assessed by the questionnaire.

Results Descriptive analyses showed that $14.2 \%$ and $17.1 \%$ of male and female workers did not intend to stay the current job at the age of 60 years old. Lack of intention was more prevalent in younger workers, workers with lower employment grade and workers in certain industrial sectors including electronics manufacturing industries for both genders and health care industry for female workers. Workers in these industries were also significantly younger than those in other industries. Findings from multivariate logistic regression models indicated that lack of intention to stay was associated with nonstandard work shift, higher psychosocial demands, physically demanding work, lower job control and higher job insecurity.

Conclusion A substantial proportion of workers lack of intention to stay at the current job until old age. We suggest that improving work conditions may help to keep workers in employment until old age, especially among workers in socioeconomic lower positions.

\section{P.3.17 PREVALENCE AND DISTRIBUTION OF MUSCULOSKELETAL DISCOMFORTS AND THE ASSOCIATIONS WITH WORK-RELATED ERGONOMIC AND PSYCHOSOCIAL FACTORS IN EMPLOYEES OF TAIWAN}

${ }^{1}$ Hsi-chen Liu*, ${ }^{1}$ Yawen Cheng, ${ }^{2}$ Jiune-Jye Ho. ${ }^{1}$ Institute of Health Policy and Management, College of Public Health, National Taiwan University, Taipei, Taiwan; ${ }^{2}$ Institute of Labor, Occupational Safety and Health, Ministry of Labor, New Taipei, Taiwan

\subsection{6/OEM-2019-EPI.276}

Background and objectives Musculoskeletal discomforts (MSDs) attribute greatly to work-related disability, but the social distributions of MSDs in the general working population have seldom been investigated. Moreover, although ergonomic and psychosocial factors at work are known to contribute to musculoskeletal risks, their independent effects on specific sites of MSDs have not been well assessed. This study aimed to examine the social distributions of MSDs and the associations of ergonomic and psychosocial work factors 
with the risks of MSDs of different bodily sites in general employees of Taiwan.

Methods Participants were representative employees aged 2565 years from a nationwide survey of 2016. Self-administered questionnaires were used to obtain information concerning work-related ergonomic and psychosocial factors, employment conditions, and MSDs of different bodily sites over the past 12 months.

Results A total of 5242 male and 4164 female employees was included. Workers who were older, with lower education levels, being manual skilled or low skilled workers, worked in the construction industry, and being employed in small-sized enterprises had higher risks for MSDs, and the most common bodily site were the neck/shoulders, low back, and wrists/ hands. Psychological demands, workplace justice and ergonomic factors were significantly associated with MSDs. Furthermore, results of separate regression models performed for MSDs of different bodily sites showed that higher psychological demands and lower workplace justice were associated with MSDs of the neck/shoulders to a greater extent than other work-related factors, while whole-body-related ergonomic factors and hand-related ergonomic factors were more greatly associated with MSDs of lower back and wrists/hands, respectively.

Conclusions MSDs were more prevalent in workers with lower socioeconomic positions. Differential contribution of specific types of work-related ergonomic and psychosocial factors to the risks of specific types of MSDs should be taken into consideration in the management of MSDs in the workplace.

\section{P.3.18 ASSOCIATION BETWEEN NIGHTSHIFT SCHEDULE AND MENTAL HEALTH SYMPTOMS AMONG FACTORY WORKERS: A CROSS-SECTIONAL STUDY}

Sophia Francesca Lu*. Carrs-Q, Queensland University Of Technology, Brisbane, Australia

\subsection{6/OEM-2019-EPI.277}

Introduction Nightshift is one of the major issues in worktime schedule. The association between working at night and the occurrence of mental health symptoms has been a subject of considerable debate. This study aimed to look at the association between working at night and mental health symptoms, and mediating factors to this association.

Methods This study looked at a database of 500 factory workers that originally investigated hazard exposures and occupational health of workers in export processing zones in the Philippines. Associations between shift schedule and probable confounders with frequency of occurrence of mental health symptoms were studied using chi-square test of association. Multiple logistic regression was used to analyze the overall association.

Results The study showed that work schedule, work load and occurrence of mental health symptoms are associated with night schedule. The crude odds ratio for the association between shift schedule and frequency of occurrence of mental health symptoms is $2.13(0.77-5.81)$. This means that without adjusting for confounders, those who work in the evening are 2.13 times more likely to have frequent occurrence of mental health symptoms as compared to those who work in the morning. Specifically, among females, those who work at night are 2.97 times more likely to have frequent occurrences of mental health symptoms compared to those who work in the morning.
Controlling for age, sex, educational attainment, tenure, work load, and exposure to occupational hazards, those who are working at night are $2.13(0.79-5.71)$ times more likely to have frequent episodes of mental health symptoms compared to those who work in the morning. Those who are frequently exposed to occupational hazards are 5.78 (1.17-28.71) times more likely to have frequent mental health symptoms.

Conclusion The study has shown that among Filipino factory workers, nightshift work is associated with mental health symptoms.

\section{P.3.19 EFFECT OF OCCUPATIONAL WORK AND SAFETY ISSUES ON ROAD CRASH INJURIES IN THE PHILIPPINES}

Sophia Francesca Lu*. Carrs-Q, Queensland University Of Technology, Brisbane, Australia

\subsection{6/OEM-2019-EPI.278}

Background This study looked at occupational road crashes and work schedule among truck and bus drivers in comparison to other drivers and motorists on the road of Metro manila which is one of the cities globally with a high traffic density. One of the most precarious work occupations is driving especially buses used for public transportation, and trucks for commercial activities. This is most astute in the metrolopolis.

Methods The study used meta-analysis of previous studies conducted, grey literature, government statistics, and validation through key database research in concerned national government agencies involved in road traffic from 2010-2015.

Results The study found that the in terms of the number of public utility vehicles registered in Metro Manila (2015), $51.27 \%$ were buses and $20.21 \%$ were trucks. Majority of the drivers worked more than 12 hours a day. In terms of time and peak of accidents, it is alarming to note that about $35 \%$ of the road crashes occurred from 22-23 gmt (2010-2015), and $30 \%$ from 23-24 (2010-2015) gmt. Human error accounted for the overwhelming cause of road crashes such as drunk driving, beating the red light, sleepiness, accounting for $99.52 \%$ in $2012,99.47 \%$ in $2013,95.33 \%$ in 2014 , and $97.19 \%$ in 2015. Majority of the drivers worked over prolonged hours on the road that may cause fatigue and sleepiness which are the highest risk factor to road accident based on the study.

Conclusion The study has shown how risky driving is as an occupation especially due to the work schedule and work issues. The study suggests developing better information, education and communication campaign as well as policies particularly on work conditions favorable to bus and truck drivers, and likewise, considering work schedule in road safety among drivers which composes one of the risky occupations.

\section{P.3.20 HOSPITALIZATION OUTCOMES OF ROAD TRAFFIC INJURY PATIENTS IN THE LARGEST HOSPITAL IN THE PHILIPPINES}

Sophia Francesca Lu*. Carrs-Q, Queensland University Of Technology, Brisbane, Australia

\subsection{6/OEM-2019-EPI.279}

Background Road traffic injuries claim are among the leading causes of preventable death, claiming around 7000 lives every year. Accordingly, injuries to the head and neck are the main causes of death and disability. 